eCommons@AKU

April 2019

\title{
Rare variant of Guillain-Barré syndrome after chikungunya viral fever
}

Sajid Hameed

Vidyasagar University

Sara Khan

Aga Khan University, sara.khan@aku.edu

Follow this and additional works at: https://ecommons.aku.edu/pakistan_fhs_mc_med_neurol Part of the Neurology Commons

\section{Recommended Citation}

Hameed, S., Khan, S. (2019). Rare variant of Guillain-Barré syndrome after chikungunya viral fever. BMJ case reports., 12(4).

Available at: https://ecommons.aku.edu/pakistan_fhs_mc_med_neurol/192 


\title{
Rare variant of Guillain-Barré syndrome after chikungunya viral fever
}

\author{
Sajid Hameed, Sara Khan
}

Neurology, Aga Khan University Hospital, Karachi, Pakistan

\section{Correspondence to} Dr Sajid Hameed, drsajidhameed92@gmail.com

Accepted 9 April 2019

\section{SUMMARY}

Chikungunya (CHIK) viral fever is a self-limiting illness that presents with severe debilitating arthralgia, myalgia, fever and rash. Neurological complications are rare. We present a case of a 36-year-old woman who presented with acute onset progressive difficulty swallowing and left arm weakness. She was diagnosed with CHIK viral fever 4 weeks prior to admission. After investigations, she was diagnosed with a pharyngeal-cervical-brachial variant of Guillain-Barré syndrome. In hospital, she required ventilator support. Her condition improved after five sessions of intravenous immunoglobulin with almost complete resolution within 6 months of symptom onset. With frequent CHIK outbreaks, the neurological complications are increasingly seen in the emergency department. The knowledge of these associations will result in early diagnosis and treatment.

\section{BACKGROUND}

Chikungunya (CHIK) fever is a self-limiting viral fever, that is, transmitted by the bite of Aedes mosquitoes, the same vectors for dengue fever. ${ }^{1}$ Multiple outbreaks of CHIK fever have occurred in Asia and Africa in the last two decades affecting millions. ${ }^{2}$ CHIK fever typically presents with fever, severe arthralgias, myalgias and skin rash. Atypical presentations with myocarditis, hepatitis and meningoencephalitis may also occur. ${ }^{3}$ Cases of transverse myelitis and Guillain-Barré syndrome (GBS) secondary to CHIK fever have been reported. ${ }^{4-6}$ Although these cases are rare, with frequent outbreaks of CHIK fever, they are increasingly being seen in clinical practice. Recognition of various neurological complications is important. We are reporting a case of a rare variant of GBS, the pharyngeal-cervical-brachial (PCB), secondarily to a CHIK infection.

\section{CASE PRESENTATION}

A 36-year-old woman presented to us with a 3-day history of difficulty swallowing followed by weakness in her left arm for 1 day. She had difficulty in swallowing both liquids and solids. It was progressive and associated with nasal regurgitation, voice changes and drooling of saliva. Her symptoms were continuous without a diurnal variation. The left arm weakness was noticed on awakening 1 day ago and was progressive. She denied symptoms of sore throat, fever, headache, neck pain, double vision, facial or limb sensory disturbances and hearing problems associated with her current symptoms.
Four weeks prior to this admission, she had experienced low-grade fever, generalised body aches and moderate pain in her joints, with predominant involvement of knees, shoulders and ankle joints. Fever subsided within the next 5-6 days; however, the joint pains persisted although the severity had decreased. She was diagnosed with having CHIK viral fever on clinical grounds and was taking analgesics on as per needed basis. There was no history of chronic illnesses.

On physical examination, she was vitally stable, awake and oriented with intact higher mental functions. Extraocular movements were intact in all directions without nystagmus. She had a hypernasal speech. Pupils were bilaterally $3 \mathrm{~mm}$ equal and reactive to light and accommodation. She had a rightsided facial palsy of lower motor neuron type. Facial sensation was intact. Gag reflex was weak and uvula was deviated to the left side. Tongue was central on protrusion with no fasciculations. On motor examination, muscle bulk and tone were normal. Power in left upper limb was reduced. Medical Research Council (MRC) grade was $3 / 5$ proximally and $4 / 5$ distally with reduced deep tendon reflexes, while power and reflexes in the remaining limbs were normal. Sensory and cerebellar examination was normal.

\section{INVESTIGATIONS}

A baseline workup, including complete blood counts, serum electrolytes and thyroid profile, was unremarkable. IgM antibodies against $\mathrm{CHIK}$ virus were detected. She underwent MRI of the brain (on day 1 ) which did not reveal any acute abnormalities. Cerebrospinal fluid (CSF) examination (on day 2) was normal with no albuminocytological dissociation. On the same day (day 2), nerve conduction studies with electromyography (EMG) revealed non-specific findings, with prolongation of bilateral R1, R2 and contralateral R2 latencies on blink testing. On EMG, voluntary motor unit action potentials had normal morphology with decreased recruitment and a rapid firing rate. In the clinical setting, these were suggestive of an early neurogenic process, possibly demyelinating in nature and a diagnosis of the PCB variant of GBS was made. Testing for antiganglioside antibodies (IgG anti-GT1a antibodies) is not available which was a limitation for definitive diagnosis.
To cite: Hameed $S$,

Khan S. BMJ Case Rep

2019;12:e228845.

doi:10.1136/bcr-2018-

228845 


\section{DIFFERENTIAL DIAGNOSIS}

Due to right-sided facial weakness, bulbar symptoms and leftsided motor weakness, our provisional diagnosis was of a posterior circulation stroke involving the brain stem. The other differentials were GBS, botulism, myasthenia gravis, postviral autoimmune demyelination or multiple sclerosis.

\section{TREATMENT}

Treatment with intravenous immunoglobulin (IVIG) was started on the second day of admission for a total of 5 days (total dose of $2 \mathrm{~g} / \mathrm{kg}$ ). On the same day (day 2), she became tachypneic with a respiratory rate of 34 breaths/min, and reduction of forced vital capacity to 500 from $1250 \mathrm{~mL}$ on the first day. Her single breath count was 12 with arterial blood gases (on $5 \mathrm{~L}$ oxygen supplementation) revealing a $\mathrm{pH}$ of $7.55, \mathrm{paCO}_{2}$ of $25.30 \mathrm{~mm} \mathrm{Hg}$, $\mathrm{paO}_{2}$ of $167.30 \mathrm{~mm} \mathrm{Hg}$ and bicarbonate of $21.80 \mathrm{mEq} / \mathrm{L}$. She was intubated and mechanically ventilated.

\section{OUTCOME AND FOLLOW-UP}

Her symptoms partially improved after the five doses of IVIG. Rehabilitation was started. Her condition gradually improved and she was discharged after 10 days with regular physiotherapy. She had normal bulbar function with MRC grade $4+/ 5$ power in the left upper limb at the sixth month of follow-up.

\section{DISCUSSION}

CHIK virus is an RNA virus that belongs to Togaviridae family. It is transmitted by the bites of mosquitoes, Aedes aegypti and Aedes albopictus. ${ }^{3}$ The word Chikungunya is derived from an African language that means 'that which bends up', named due to the symptoms of severe debilitating joint pain. ${ }^{7}$ Apart from fever, arthralgia, myalgia and skin rash, atypical presentations of hepatitis and myocarditis are also seen. ${ }^{5}$ Neurological complications are rare. Less than 1000 cases of CHIK-associated neurological disease are reported in the literature with encephalopathy being the most common complication. ${ }^{8}$ Peripheral neuropathy without central nervous system disease, including GBS, is even rarer.

GBS is a postinfectious autoimmune polyneuropathy that classically presents with an acute-onset of symmetrical, bilateral flaccid weakness. It has a median incidence rate of 1.1 per 100000 in Europe and North America. ${ }^{9}$ A twofold increase in the incidence of GBS was reported in the French West Indies during the 2014 CHIK outbreak. ${ }^{10}$ GBS is a heterogeneous disorder with multiple subtypes. The common forms of GBS are acute inflammatory demyelinating polyneuropathy, acute motor axonal neuropathy (AMAN) and acute motor sensory axonal neuropathy. The uncommon forms of GBS include Miller Fisher syndrome, Bickerstaff's brainstem encephalitis and PCB variant. ${ }^{11}$

The PCB variant of GBS typically presents with the pharyngeal, neck and upper limb weakness with associated areflexia/hyporeflexia. Power in lower limbs is normal or mildly affected. Sensations are often normal. ${ }^{12}$ Respiratory failure is not uncommon. In a study by Nagashima et al, 27\% of the patients with PCB variant GBS required endotracheal intubation. ${ }^{13}$ PCB variant is often misdiagnosed with brainstem stroke or myasthenia gravis. Electrophysiological studies and CSF albuminocytological dissociation (ie, high levels of protein with normal cell counts) help in the diagnosis but they can be normal in the early disease. ${ }^{12}$ Nerve conduction studies usually show a localised pattern of axonal damage similar to AMAN. Further, the presence of IgG anti-GT1a antibodies is strongly associated with the PCB variant. ${ }^{12}$

GBS is a treatable condition. Plasma exchange and IVIG are equally effective in reducing the nerve damage and hastening the recovery if given early in the disease within the first 2 weeks. Patients should be observed in a critical care unit for dysautonomia and respiratory compromise. Mechanical ventilation may be needed. ${ }^{15}$ With the current CHIK viral fever pandemic, the caregivers should be aware of neurological complications for their early diagnosis and treatment to decrease morbidity and mortality.

\section{Learning points}

- Chikungunya (CHIK) viral fever is associated with neurological complications, although rare.

- Cases of meningoencephalitis, transverse myelitis and Guillain-Barré syndrome in association with CHIK viral fever have been reported in the literature.

- High clinical suspicion, prompt diagnosis and treatment are important for a good neurological outcome.

Contributors The case was initially seen by SH and was discussed with SK who gave the design for the case report. SH reviewed the literature and wrote the initia and revised draft. SK reviewed it and advised suggestions and corrections, which were performed by SH. Both SH and SK participated in case writing.

Funding The authors have not declared a specific grant for this research from any funding agency in the public, commercial or not-for-profit sectors.

Competing interests None declared.

Patient consent for publication Obtained.

Provenance and peer review Not commissioned; externally peer reviewed.

\section{REFERENCES}

1 Sam IC, AbuBakar S. Chikungunya virus infection. Med J Malaysia 2006;61:264-9.

2 Staples JE, Breiman RF, Powers AM. Chikungunya fever: an epidemiological review of a re-emerging infectious disease. Clin Infect Dis 2009;49:942-8.

3 Caglioti C, Lalle E, Castilletti C, et al. Chikungunya virus infection: an overview. New Microbiol 2013;36:211-7

4 Singh Jain R, Khan I, Kumar Saini P. Longitudinally extensive transverse myelitis caused by Chikungunya virus. Indian Journal of Medical Specialities 2017;8:48-50.

5 Agarwal A, Vibha D, Srivastava AK, et al. Guillain-Barre syndrome complicating chikungunya virus infection. J Neurovirol 2017;23:504-7.

6 Lebrun G, Chadda K, Reboux AH, et al. Guillain-Barré syndrome after chikungunya infection. Emerg Infect Dis 2009;15:495-6.

7 Simon $F$, Javelle E, Oliver M, et al. Chikungunya virus infection. Curr Infect Dis Rep 2011;13:218-28

8 Mehta R, Gerardin P, de Brito CAA, et al. The neurological complications of chikungunya virus: A systematic review. Rev Med Virol 2018;28:e1978.

9 Sejvar JJ, Baughman AL, Wise M, et al. Population incidence of GuillainBarré syndrome: a systematic review and meta-analysis. Neuroepidemiology 2011;36:123-33.

10 Balavoine S, Pircher M, Hoen B, et al. Guillain-Barré Syndrome and Chikungunya: Description of All Cases Diagnosed during the 2014 Outbreak in the French West Indies. Am J Trop Med Hyg 2017;97:356-60.

11 Hiew FL, Ramlan R, Viswanathan S, et al. Guillain-Barré Syndrome, variants \& forms fruste: Reclassification with new criteria. Clin Neurol Neurosurg 2017;158:114-8.

12 Wakerley BR, Yuki N. Pharyngeal-cervical-brachial variant of Guillain-Barré syndrome. J Neurol Neurosurg Psychiatry 2013;25.

13 Nagashima T, Koga M, Odaka M, et al. Continuous spectrum of pharyngeal-cervicalbrachial variant of Guillain-Barré syndrome. Arch Neurol 2007;64:1519-23.

14 Diagnosis vanDPA. treatment and prognosis of Guillain-Barré syndrome (GBS). La Presse Médicale 2013;42:e193-201.

15 Dimachkie MM, Barohn RJ. Guillain-Barré syndrome and variants. Neurol Clin 2013;31:491-510. 
Copyright 2019 BMJ Publishing Group. All rights reserved. For permission to reuse any of this content visit https://www.bmj.com/company/products-services/rights-and-licensing/permissions/

BMJ Case Report Fellows may re-use this article for personal use and teaching without any further permission.

Become a Fellow of BMJ Case Reports today and you can:

- Submit as many cases as you like

- Enjoy fast sympathetic peer review and rapid publication of accepted articles

Access all the published articles

- Re-use any of the published material for personal use and teaching without further permission

For information on Institutional Fellowships contact consortiasales@bmjgroup.com

Visit casereports.bmj.com for more articles like this and to become a Fellow 